\begin{tabular}{|c|c|}
\hline Title & A biaryl sulfonamide derivative as a novel inhibitor of filovirus infection \\
\hline Author(s) & $\begin{array}{l}\text { Isono, Mao; Furuy ama, Wakako; Kuroda, Makoto; Kondoh, Tatsunari; Igarashi, Manabu; Kajihara, Masahiro; Y oshida, } \\
\text { Reiko; Manzoor, Rashid; Okuya, Kosuke; Miyamoto, Hiroko; Feldmann, Heinz; Marzi, A ndrea; Sakaitani, Masahiro; } \\
\text { Nanbo, A suka; T akada, A y ato }\end{array}$ \\
\hline Citation & $\begin{array}{l}\text { A ntiviral research, } 183,104932 \\
\text { https://doi.org/10.1016/.antiviral.2020.104932 }\end{array}$ \\
\hline Issue Date & $2020-11$ \\
\hline Doc URL & http:/hdl. handle.net/2115/83372 \\
\hline Rights & $\begin{array}{l}\text { (0) 2020. This manuscript version is made available under the CC-BY-NC-ND } 4.0 \text { license } \\
\mathrm{https} / / \text { / reativecommons.org/icenses/by-nc-nd/4.0/ }\end{array}$ \\
\hline Rights(URL) & https:/creativecommons.org/icenses/by-nc-nd/4.0/ \\
\hline Type & article (author version) \\
\hline File Information & isono et al_no page and linenumber R2_clean.pdf \\
\hline
\end{tabular}

Instructions for use 


\section{A biaryl sulfonamide derivative as a novel inhibitor of filovirus infection}

Mao Isono ${ }^{\mathrm{a}}$, Wakako Furuyama ${ }^{\mathrm{a}, \uparrow}$, Makoto Kuroda ${ }^{\mathrm{a}, \uparrow}$, Tatsunari Kondoh ${ }^{\mathrm{a} \dagger}$, Manabu Igarashi $^{\mathrm{a}, \mathrm{b}}$, Masahiro Kajihara ${ }^{\mathrm{a}, \dagger}$, Reiko Yoshida ${ }^{\mathrm{a}}$, Rashid Manzoor ${ }^{\mathrm{a}}$, Kosuke Okuya ${ }^{\mathrm{a}}$, Hiroko Miyamoto $^{\mathrm{a}}$, Heinz Feldmann ${ }^{\mathrm{c}}$, Andrea Marzi ${ }^{\mathrm{c}}$, Masahiro Sakaitani ${ }^{\mathrm{d}}$, Asuka $\mathrm{Nanbo}^{\mathrm{e}}$, Ayato Takada ${ }^{\mathrm{a}, \mathrm{b}, \mathrm{f}, *}$

aDivision of Global Epidemiology, Research Center for Zoonosis Control, Hokkaido University, Sapporo, Japan

${ }^{\mathrm{b}}$ Global Station for Zoonosis Control, Global Institution for Collaborative Research and Education, Hokkaido University, Sapporo, Japan

'Laboratory of Virology, Division of Intramural Research, National Institute of Allergy and Infectious Diseases, National Institutes of Health, Hamilton, Montana, United States of America

${ }^{\mathrm{d}}$ Lilac Pharma. Co., Sapporo, Japan

'The National Research Center for the Control and Prevention of Infectious Diseases, Nagasaki University, Nagasaki, Japan

fDepartment of Disease Control, School of Veterinary Medicine, University of Zambia, Lusaka, Zambia

$\dagger$ Current address

Wakako Furuyama: Laboratory of Virology, Division of Intramural Research, National Institute of Allergy and Infectious Diseases, National Institutes of Health, Hamilton, Montana, United States of America 
Makoto Kuroda: Influenza Research Institute, Department of Pathobiological Sciences, School of Veterinary Medicine, University of Wisconsin-Madison, Madison, Wisconsin, United States of America

Tatsunari Kondoh: Tsukuba Branch, WDB Co., Ltd., 1-6-1 Takezono, Tsukuba, Ibaraki, 305-0032, Japan

Masahiro Kajihara: Hokudai Center for Zoonosis Control in Zambia, Research Center for Zoonosis Control, Hokkaido University, Sapporo, Japan

*Corresponding author (A. Takada)

Division of Global Epidemiology, Hokkaido University

Research Center for Zoonosis Control, Kita-20, Nishi-10, Kita-ku, Sapporo 001-0020, Japan. Tel: +81-11-706-9502 Fax: +81-11-706-7310

E-mail address: atakada@czc.hokudai.ac.jp 


\begin{abstract}
Ebolaviruses and marburgviruses, members of the family Filoviridae, are known to cause fatal diseases often associated with hemorrhagic fever. Recent outbreaks of Ebola virus disease in West African countries and the Democratic Republic of the Congo have made clear the urgent need for the development of therapeutics and vaccines against filoviruses. Using replication-incompetent vesicular stomatitis virus (VSV) pseudotyped with the Ebola virus (EBOV) envelope glycoprotein (GP), we screened a chemical compound library to obtain new drug candidates that inhibit filoviral entry into target cells. We descovered a biaryl sulfonamide derivative that suppressed in vitro infection mediated by GPs derived from all known human-pathogenic filoviruses. To determine the inhibitory mechanism of the compound, we monitored each entry step (attachment, internalization, and membrane fusion) using lipophilic tracer-labelled ebolavirus-like particles and found that the compound efficiently blocked fusion between the viral envelope and the endosomal membrane during cellular entry. However, the compound did not block the interaction of GP with the Niemann-Pick $\mathrm{C} 1$ protein, which is believed to be the receptor of filoviruses. Using replication-competent VSVs pseudotyped with EBOV GP, we selected escape mutants and identified two EBOV GP amino acid residues (positions 47 and 66) important for the interaction with this compound. Interestingly, these amino acid residues were located at the base region of the GP trimer, suggesting that the compound might interfere with the GP conformational change required for membrane fusion. These results suggest that this biaryl sulfonamide derivative is a novel fusion inhibitor and a possible drug candidate for the development of a pan-filovirus therapeutic.
\end{abstract}




\section{Keywords}

Ebolavirus, Marburgvirus, Glycoprotein, Compound, Entry inhibitor, Membrane fusion

\section{Introduction}

Ebola- and marburgviruses are non-segmented negative-stranded RNA viruses that belong to the family Filoviridae, which includes among others the genus Marburgvirus with a single species, Marburg marburgvirus, including Marburg virus (MARV) and Ravn virus, and the genus Ebolavirus with five species, Zaire ebolavirus, Sudan ebolavirus, Tai Forest ebolavirus, Bundibugyo ebolavirus, and Reston ebolavirus, represented by Ebola virus (EBOV), Sudan virus (SUDV), Taï Forest virus (TAFV), Bundibugyo virus (BDBV), and Reston virus (RESTV), respectively (Sahul Hameed et al., 2019). An additional ebolavirus species, Bombali ebolavirus, represented by Bombali virus (BOMV), has been proposed recently (Goldstein et al., 2018). These filoviruses, with the exception of RESTV and BOMV, are known to cause severe hemorrhagic fever in humans (Emanuel et al., 2018; Rollin et al., 1999). The case fatality rate is up to about 90\% but varies among virus species and even variants (Baseler et al., 2017).

EBOV caused the largest outbreak of Ebola virus disease (EVD) in 2013-2016 in West Africa, with over 28,000 cases and 11,000 deaths. In the second largest EVD outbreak in the Democratic Republic of the Congo (DRC), declared by the Ministry of Health of the DRC on $1^{\text {st }}$ August 2018, a total of 3,481 EVD confirmed and probable cases and 2,299 deaths have been reported (as of July 3, 2020) (Mbala-Kingebeni et al., 2019; Tariq et al., 2019; WHO, 2019). Clinical trials of antibody therapies (i.e., ZMapp, REGN-EB3, and mAb114) were conducted during the outbreaks in West Africa and the DRC (The PREVAIL II Writing Group, 2016; WHO, 2018). Several small compound 
candidates for treatment of EVD such as T-705 (favipiravir), and GS-5734 (remdesivir), all of which are nucleotide analogues, have also been tested in animal models and clinical cases (Cardile et al., 2016; Nakkazi, 2018; Sissoko et al., 2016). In particular, remdesivir is currently under clinical trials in the DRC (NIH, 2019). However, there are no approved antiviral therapeutics against EVD.

The ebolaviruses contain at least seven structural proteins: nucleoprotein (NP), viral protein (VP) 35, VP40, glycoprotein (GP), VP30, VP24, and RNA-dependent RNA polymerase (L). GP is the only viral surface protein that forms spikes on the virion surface: It is responsible for receptor binding and membrane fusion (Hunt et al., 2012; Takada et al., 1997) and thus is thought to be an important target of antivirals. The entry of ebolaviruses into host cells is initiated by attachment of GP to cell surface attachment receptors such as C-type lectins and TIM-1 (Alvarez et al., 2002; Kondratowicz et al., 2011; Takada et al., 2004). The virus particle is then internalized into endosomes by macropinocytosis (Nanbo et al., 2010; Saeed et al., 2010). In endosomes, GP is proteolytically processed by cathepsins B and L in a low $\mathrm{pH}$ environment (Schornberg et al., 2006). The processed GP interacts with the endosomal fusion receptor, Niemann-Pick C1 (NPC1), and subsequently fusion between the viral envelope and the endosomal membrane occurs, leading to the release of the viral ribonucleoprotein (RNP) complex into cytoplasm (Carette et al., 2011; Côté et al., 2011). The RNP complex is formed by the genomic RNA, NP, VP24, VP35, VP30, and L. EBOV VP35 and VP24 are known interferon antagonists (Basler et al., 2000; Zhang et al., 2012). VP40, the matrix protein, is the most abundant protein in the virus particle and plays a key role in the budding from infected cells (Jasenosky and Kawaoka, 2004; Noda et al., 2002).

We discovered a novel compound, HUP2976, that specifically inhibits the entry 
of filoviruses into target cells. We determined the inhibitory mechanism of this drug candidate by monitoring each step of the viral entry process (attachment, internalization, and membrane fusion) using virus-like particles (VLPs) consisting of EBOV NP, VP40, and GP. HUP2976 efficiently blocked the membrane fusion in cellular endosomes, though it did not inhibit VLP binding to the NPC1 receptor, suggesting that the mechanism of action of HUP2976 was fusion inhibition independent from the GP-NPC1 engagement.

\section{Materials and Methods}

\subsection{Cells and cellular assays}

Human embryonic kidney (HEK) 293T, African green monkey kidney Vero E6, NPC1-knockout Vero E6 (Vero E6/NPC1-KO) (Kondoh et al., 2018), eGFP-Rab7expressing Vero E6 (Vero E6/eGFP-Rab7) kindly provided by Dr. A. Nanbo, Nagasaki University, Japan, and human hepatoma Huh7 cells were grown in Dulbecco's modified Eagle's medium (DMEM) (Sigma) supplemented with 10\% fetal calf serum (FCS) (Cell Culture Bioscience), $100 \mathrm{U} / \mathrm{ml}$ penicillin, and $0.1 \mathrm{mg} / \mathrm{ml}$ streptomycin (Gibco). Cell viabilities were measured with the alamar blue assay (Biosource International) according to the manufacturer's instructions. Endosomal $\mathrm{pH}$ in Vero E6/eGFP-Rab7 was tested using LysoTracker Red DND-99 (Life Technologies).

\subsection{Vesicular stomatitis virus (VSV) pseudotyped with filovirus GPs}

The expression plasmids for filovirus GPs were constructed as described previously (Takada et al., 1997). Mutant GP genes were constructed by site-directed mutagenesis with KOD-Plus Neo (Toyobo). Using vesicular stomatitis virus (VSV) containing the green fluorescent protein (GFP) gene instead of the VSV glycoprotein (G) 
gene (VSV $\left.\Delta \mathrm{G}^{*}-\mathrm{G}\right)$, GP-expressing plasmids, and HEK293T cells, replicationincompetent VSVs pseudotyped with ebolavirus and marburgvirus GPs were generated as described previously (Furuyama et al., 2017; Takada et al., 1997). VSVs pseudotyped with GPs of EBOV (Mayinga), BDBV (Butalya), TAFV (Pauléoula), SUDV (Boniface), RESTV (Pennsylvania), and MARV (Angola) were preincubated with an anti-VSV G monoclonal antibody, VSV-G [N] 1-9, to abolish the background infectivity of parental VSV $\Delta \mathrm{G}^{*}-\mathrm{G}$ (Nakayama et al., 2011). For virus titration, 10-fold serial dilutions of pseudotyped VSVs were inoculated into confluent monolayers of Vero E6 cells cultured on 96-well plates, and infectious units (IUs) were determined $18 \mathrm{hr}$ later by counting the number of GFP-expressing cells with IN Cell Analyzer (GE Healthcare).

Replication-competent recombinant VSV (rVSV-EBOV) was generated as described previously (Takada et al., 2003) and its titer was determined by a conventional plaque assay. Briefly, Vero E6 cells were seeded on 12-well plates $\left(3.0 \times 10^{5}\right.$ cells/well $)$ and incubated in a $5 \% \mathrm{CO}_{2}$ incubator at $37^{\circ} \mathrm{C}$ for $18 \mathrm{hr}$. After aspirating the medium, serial dilutions (10-fold) of rVSV-EBOV were inoculated (100 $\mu \mathrm{l} /$ well) onto the cells. After incubation in a $5 \% \mathrm{CO}_{2}$ incubator at $37^{\circ} \mathrm{C}$ for $1 \mathrm{hr}$ with rocking every $15 \mathrm{~min}$, the inoculum was removed and cells were washed with FCS free-DMEM. Following this, they were overlaid with Eagle's minimal essential medium (MEM) (Invitrogen) containing 1.0\% Bacto Agar (BD), 0.3\% bovine serum albumin (BSA)(Sigma), $100 \mathrm{U} / \mathrm{ml}$ penicillin, and $0.1 \mathrm{mg} / \mathrm{ml}$ streptomycin, and then incubated in $5 \% \mathrm{CO}_{2}$ incubator at $37^{\circ} \mathrm{C}$ for $48 \mathrm{hr}$. Numbers of plaques at appropriate dilutions were counted to determine plaque forming units (PFU).

\subsection{Recombinant EBOV}


Recombinant EBOV encoding GFP (EBOV-GFP) was generated as described previously (Ebihara et al., 2007). EBOV-GFP was inoculated onto confluent monolayers of Vero E6 cells and incubated for $1 \mathrm{hr}$. Then the inoculum was removed and a 1.2\% carboxymethyl cellulose (CMC)/MEM solution was added. Following incubation for 23 days at $37^{\circ} \mathrm{C}$, images were captured by fluorescent microscopy. Numbers of GFPexpressing foci were counted under a microscope. All infectious work with EBOV-GFP was performed in the biosafety level-4 laboratory at the Integrated Research Facility of the Rocky Mountain Laboratories, Division of Intramural Research, National Institute of Allergy and Infectious Diseases, National Institutes of Health, Hamilton, Montana, USA. All standard operating procedures were approved by the Institutional Biosafety Committee.

\subsection{Screening of the compounds}

A chemical compound library consisting of 9,600 compounds was provided by the Drug Development Initiative (DDI), University of Tokyo. Vero E6 cells were seeded on 96 -well plates $\left(3.0 \times 10^{4}\right.$ cells/well $)$ and incubated for $18 \mathrm{hr}$. Then equal volumes of VSVs pseudotyped with filovirus GPs (1000 IUs/ml) diluted in DMEM with 2\% FCS and $\mathrm{P} / \mathrm{S}$ and chemical compounds $(10 \mu \mathrm{M})$ were mixed, and added to theVero E6 cells (100 $\mu \mathrm{l} /$ well). After $18 \mathrm{hr}$ incubation in a $5 \% \mathrm{CO}_{2}$ incubator at $37^{\circ} \mathrm{C}$, GFP-expressing cells were counted using IN Cell Analyzer (GE Healthcare).

\subsection{DiI assay}

VLPs containing EBOV GP, VP40, and NP were purified as described previously (Furuyama et al., 2016; Nanbo et al., 2010). VLPs were labeled with a lipophilic tracer, 
1,1'-dioctadecyl-3,3,3',3'-tetramethylindocarbocyanine perchlorate (DiI) (Invitrogen) at room temperature with gentle rocking in the dark for $1 \mathrm{hr}$. Labeled VLPs were diluted with PBS to $1 \mu \mathrm{g} / \mathrm{ml}$. Vero E6/eGFP-Rab7 cells $\left(1.5 \times 10^{5}\right.$ cells/well) were cultured in 8 well chamber slides (Merck). Then they were washed with $250 \mu 1$ of FCS-free DMEM and incubated with DiI-labelled VLPs on ice for $30 \mathrm{~min}$. The cells were washed with FCSfree DMEM to remove unbound VLPs and incubated with $250 \mu 1$ of DMEM containing HUP2976 $(25 \mu \mathrm{M})$ for 0,2 , and $6 \mathrm{hr}$ at $37^{\circ} \mathrm{C}$ to analyze attachment, internalization, and membrane fusion, respectively. In this assay, the fluorescent signal is enhanced once the DiI-labelled VLP envelope fuses with the endosomal membrane (Nanbo et al., 2010). To count the number of DiI-labelled VLPs, the cells were fixed with 4\% paraformaldehyde for $15 \mathrm{~min}$ at room temperature. Then nuclei were stained with $1 \mu \mathrm{g} / \mathrm{ml} \mathrm{4}$ ',6-diamidino-2phenylindole, dihydrochloride (DAPI) for $10 \mathrm{~min}$ at room temperature. Images were captured with a $63 \times$ oil objective lens using a Zeiss LSM780 inverted microscope and a ZEN 2010 software. Images of 4-20 optical sections were acquired in 0.5-1.0 $\mu \mathrm{m}$ steps to analyze the number of DiI-labeled VLPs $(0 \mathrm{hr})$, the percentage of DiI-labeled VLPs that colocalized with eGFP-Rab7 (2 hr), and relative sizes and intensities of DiI dots (6 hr). Quantitative analyses were conducted with Image J software (NIH, USA).

\subsection{GP-NPC1 binding assay}

Vero E6/NPC1-KO cells and Vero E6/NPC1-KO cells expressing HA-tagged NPC1 (Kondoh et al., 2018) were seeded in T-75 flasks. After harvesting with trypsin, the cells were sedimented at 1,000 rpm for $5 \mathrm{~min}$. CHAPS-NTE buffer $(0.5 \% \mathrm{wt} / \mathrm{vol} \mathrm{CHAPS}$, 140 mM NaC1, 10 mM Tris-HC1, 1 mM EDTA; pH 7.5) (Miller et al., 2012) was added to cells to a final concentration of $10^{7}$ cells $/ \mathrm{ml}$. Then, EDTA-free Complete Protease 
Inhibitor Cocktail (Roche) was added. The cells were sedimented at $10,000 \times \mathrm{g}$ for 10 min at $4^{\circ} \mathrm{C}$ and the supernatant was harvested. VLPs $(1 \mathrm{mg} / \mathrm{ml}$ in PBS $)$ were treated with thermolysin (Sigma) at $37^{\circ} \mathrm{C}$ for $30 \mathrm{~min}$. The VLP solution was diluted at 1:10 with 0.05 M carbonate buffer ( $\mathrm{pH}$ 9.6). ELISA plates (Nunc, Maxisorp) were coated with the diluted VLPs, and incubated at $4{ }^{\circ} \mathrm{C}$ overnight. The VLPs were removed and the plates were blocked with BSA (10 mg/ml in PBS) and incubated at room temperature for $2 \mathrm{hrs}$. Recombinant monoclonal antibody mAb114, which blocks binding of NPC1 to GP via interaction with the glycan cap and the inner chalice of GP, was generated as a positive control based on the sequence described previously using $\gamma 1 \mathrm{HC}$, and $\kappa \mathrm{LC}$ vectors (Cagigi et al., 2018; Saito et al., 2019; Tiller et al., 2008). Serially diluted HUP2976 and mAb114 (in PBS) were mixed with cell lysates (diluted at 1:20 with CHAPS-NTE buffer) and incubated at room temperature for $10 \mathrm{~min}$. After washing the plates with $0.05 \%$ Tween 20 in PBS (PBST), the mixture was added to each well and incubated at $4^{\circ} \mathrm{C}$ overnight. After removal of the mixture, the plates were washed with PBST 3 times, and rat anti-HA antibody 3F10 (Sigma) diluted with PBST containing BSA $(5 \mathrm{mg} / \mathrm{ml})$ was added, followed by incubation at room temperature for $1 \mathrm{hr}$. After washing 3 times with PBST, horseradish peroxidase (HRP)-conjugated anti-rat $\operatorname{IgG}(\mathrm{H}+\mathrm{L})$ (Jackson ImmunoResearch) was added to each well. After incubation at room temperature for $1 \mathrm{hr}$, the plates were extensively washed and a 3,3',5,5'-tetramethyl-benzidine (TMB) substrate (Sigma) was added, followed by incubation in the dark at room temperature for 30-60 min. The optical density (OD) value at $450 \mathrm{~nm}$ was measured after stopping the reaction with $1 \mathrm{M}$ phosphoric acid.

\subsection{Selection of HUP2976 escape mutants}


Tenfold serial dilutions of rVSV-EBOV (approximately $2.0 \times 10^{2}$ to $2.0 \times 10^{6}$ PFU/0.1 ml in FCS free-DMEM) were mixed with equal volumes of HUP2976 (20 $\mu \mathrm{M}$ in FCS free-DMEM) and incubated at room temperature for $1 \mathrm{hr}$, then inoculated onto confluent Vero E6 cells grown in 6-well tissue culture plates. After adsorption for $1 \mathrm{hr}$, the cells were overlaid with MEM (Invitrogen) containing 1.0\% Bacto Agar (BD) and 20 $\mu \mathrm{M}$ HUP2976, and then incubated in a $5 \% \mathrm{CO}_{2}$ incubator at $37^{\circ} \mathrm{C}$ for $48 \mathrm{hrs}$. Mutant viruses growing in the presence of HUP2976 were purified from single isolated plaques and propagated on Vero E6 cells. Viral RNAs were extracted from the supernatant, the nucleotide sequences of the GP genes of the parent viruses and the escape mutants were determined and the amino acid sequences were compared among the viruses.

\section{Results}

\subsection{Inhibitory effect of HUP2976 against VSVs pseudotyped with filovirus GPs}

Using VSV pseudotyped with EBOV GP, a total of 9,600 compounds from the DDI of the University of Tokyo were screened for antiviral effects (i.e., entry inhibitors), and we obtained approximatey 100 compounds that inhibited the virus entry into target cells. Based on the structural simplicity, potential toxicity data, and antiviral efficacy, we selected a biaryl sulfonamide derivative. The structure-activity correlation of derivatives of this lead compound enabled us to improve the inhibitory activity and the cytotoxicity (data not shown) and, thus, we obtained a viable drug candidate, HUP2976 (Fig. 1A).

We found that HUP2976 efficiently inhibited infection by VSVs pseudotyped with filovirus GPs, but not VSV G in Vero E6 and Huh7 cells, suggesting the potential of HUP2976 to specifically inhibit the entry of filoviruses (Fig. 1B). Notably, VSV pseudotyped with EBOV or BDBV GPs was almost completely neutralized at $0.31 \mu \mathrm{M}$ 
in both Vero E6 and Huh7 cells. Among ebolaviruses, HUP2976 showed the weakest effect on RESTV GP-mediated infection. Although HUP2976 showed less efficacy against VSV pseudotyped with MARV GP, it reduced the infectivity at $5 \mu \mathrm{M}$ in both Vero E6 and Huh7 cells (Fig. 1B). The 50\% inhibitory concentrations ( IC $\left._{50}\right)$ of HUP2976 for pseudotyped VSVs using Vero E6 cells were $0.086 \mu \mathrm{M}$ (EBOV GP), $0.270 \mu \mathrm{M}$ (SUDV GP), $0.307 \mu \mathrm{M}$ (TAFV GP), $0.050 \mu \mathrm{M}$ (BDBV GP), $1.117 \mu \mathrm{M}$ (RESTV GP), and 4.79 $\mu \mathrm{M}$ (MARV GP). Regarding Huh7 cells, IC50 of HUP2976 for pseudotyped VSVs were $0.010 \mu \mathrm{M}$ (EBOV GP), $0.020 \mu \mathrm{M}$ (SUDV GP), $0.151 \mu \mathrm{M}$ (TAFV GP), $0.010 \mu \mathrm{M}$ (BDBV GP), $0.280 \mu \mathrm{M}$ (RESTV GP), and $0.570 \mu \mathrm{M}$ (MARV GP). Significant cytotoxicity was not observed in both cell lines except the highest concentration $(80 \mu \mathrm{M})$ for Huh7 cells. Dose-dependent inhibitory effects of HUP2976 on EBOV entry were confirmed using infectious EBOV-GFP (Fig. 2). We found that sizes of virus-infected cell foci formed in the presence of HUP2976 were markedly smaller than in control cells treated with $0.5 \%$ DMSO, and that HUP2976 significantly reduced the number of visible foci formed by EBOV-GFP (Fig. 2). The IC50 value for EBOV-GFP was around $0.1 \mu \mathrm{M}$, which was similar to that for VSV pseudotyped with EBOV GP in Vero E6 cells.

\subsection{Inhibition of fusion between virus and endosomal membrane by HUP2976}

We then investigated the inhibitory effects of HUP2976 on viral attachment (0 $\mathrm{hr}$ ), internalization (2 hr), and membrane fusion (6 hr) using DiI-labelled VLPs consisting of EBOV NP, VP40, and GP (Fig. 3). The number of VLPs attached to the surface of Vero E6 cells in the presence of HUP2976 was not significantly different from that of untreated (i.e., DMSO-treated) cells, indicating that HUP2976 did not interfere with VLP attachment (Fig. 3A, B). Likewise, the number of VLPs colocalizing with eGFP-Rab7, a 
late endosome marker, was similar for HUP2976-treated and untreated cells, suggesting that HUP2976 did not affect subsequent uptake of VLPs into cellular endosomes (Fig. 3C, D). Finally, we analyzed membrane fusion efficiency by detecting dequenched DiI fluorescence signals (Kuroda et al., 2015; Nanbo et al., 2010). In this assay, when DiIlabeled VLP envelopes fuse with the endosomal membrane, enhanced fluorescent signals are observed. We observed significantly enhanced DiI signals colocalizing with Rab7 in untreated cells, indicating that membrane fusion occurred efficiently in endosomes (Fig. 3E, F). In contrast, dequenched DiI signals were significantly reduced in the presence of HUP2976, indicating that HUP2976 prevented GP-mediated membrane fusion in endosomes (Fig. 3E, F). Using a LysoTracker marker, we examined endosomal acidification in the presence or absence of HUP2976 and found that this compound did not significantly raise the endosomal pH (Fig. 3G).

\subsection{Effects of HUP2976 and mAb114 on EBOV GP-NPC1 binding}

Since EBOV GP is known to bind the endosomal fusion receptor NPC1 to mediate membrane fusion, we conducted EBOV GP-NPC1 binding assays to examine whether the interaction between EBOV GP and NPC1 was inhibited by HUP2976. Consistent with a previous study (Misasi et al., 2016), the positive control antibody mAb114, which binds to the NPC1 binding region of EBOV GP, inhibited the interaction of these molecules in a dose-dependent manner (Fig. 4). In contrast, HUP2976 did not reduce the binding activity of EBOV GP to NPC1 even at the highest concentration tested (Fig. 4). These results indicated that HUP2976 did not affect the interaction between EBOV GP and NPC1. 


\subsection{Amino acid substitutions in the EBOV GP escape mutants}

To identify amino acid residues that could potentially interact with HUP2976, escape mutants were selected using replication-competent rVSV-EBOV. We isolated 6 escape mutants, and amino acid substitutions in the GP genes were analyzed (Fig. 5A). All the GP mutants had amino acid substitutions at positions 47 (Asp-to-Gly [1/6] or Aspto-Glu [1/6]) or 66 (Val-to-Phe [4/6]), both of which are located in the base region (amino acid positions 33-70) of the GP molecule (Fig. 5B) (King et al., 2018).

After cloning these mutant GP genes into expression vectors, VSVs pseudotyped with mutant GPs were prepared to analyze whether these amino acid substitutions affected the inhibitory efficacy of HUP2976 (Fig. 5C). We found that single substitutions at position 47 and 66 similarly reduced the sensitivity of the virus to HUP2976 as indicated by approximately 60 - to 100 -fold increased $\mathrm{IC}_{50}$ values. There was no significant difference in the extent of the resistance among the mutants with single and double substitutions, indicating that either of the mutations at position 47 or 66 was sufficient to escape from the inhibitory effect of HUP2976. However, it is worth noting that neither single nor multiple mutations in GP made the virus fully resistant to this compound. The amino acid residues at positions 47 and 66 mapped on the GP trimeric structure (PDB code: 5JQ3) revealed that the distance between $\mathrm{C} \alpha$ atoms of these two residues was $19.9 \AA$ (in a GP monomer) in the base region of the chalice-like GP structure (Fig. 6). The distances from positions 47 to 47, from 66 to 66, and from 47 to 66 between the GP monomers were $37.8 \AA, 33.3 \AA$, and $28.0 \AA$, respectively. Interestingly, D47 and V66 were located in the same cavity formed by 2 neighboring GP monomers (Fig. 6B).

\section{Discussion}


During the epidemic of EVD in West Africa, favipiravir (T-705), a viral RNA polymerase inhibitor approved for conditional use to treat influenza virus infections in Japan, was investigated for treatment of EVD patients (Bai et al., 2016; Sissoko et al., 2016). However, its therapeutic potency remains questionable due to the limited efficacy for patients with high EBOV titers. Other experimental drugs such as remdesivir have also been used in the latest outbreak in the DRC. All these chemical compound-based drug candidates are nucleotide analogues expected to interfere with the function of the viral RNA polymerase L. HUP2976 inhibits ebolavirus infection by blocking the entry of these viruses into cells. We found that HUP2976 had the potential to inhibit GP-mediated infection with VSV pseudotypes carrying GPs of representative members of all known human-pathogenic filovirus species. Notably, the inhibitory effects on EBOV GP- and BDBV GP-mediated infection were particularly strong. Our data suggest that HUP2976 may be a pan-filovirus therapeutic.

We found that HUP2976 inhibited fusion between the endosomal membrane and viral envelope. It has been shown that low endosomal $\mathrm{pH}$ leads to proteolytic processing of filovirus GPs during the transport of filovirus particles to late endosomes, and the exposed receptor binding site of the proteolytically processed GP is thought to interact with NPC1, followed by membrane fusion (Carette et al., 2011; Côté et al., 2011). Since the endosomal $\mathrm{pH}$ was not significantly changed in HUP2976-treated cells, it is unlikely that altered acidification conditions affected the viral infectivity. The fact that HUP2976 did not reduce the infectivity of $\operatorname{VSV} \Delta \mathrm{G}^{*}-\mathrm{G}$ supports this notion. Thus, we first hypothesized that HUP2976 inhibited the binding between GP and NPC1. However, contrary to our expectation, the binding of these molecules was not blocked by HUP2976. By analyzing the GP sequences of escape mutants, we found that amino acid residues 
D47 and V66 might be important for the antiviral effect of HUP2976. These amino acid residues are well conserved among ebolaviruses and located in the base region (Fig. 5D), and seem to be important to form or stabilize the trimeric structure of GP.

Recently, selective estrogen receptor modulators (SERM), painkillers, antianginals antidepressants, and antipsychotics have been reported to have potential as fusion inhibitors against ebolaviruses (Johansen et al., 2015; Shaikh et al., 2019; Zhao et al., 2018, 2016). While clomiphene, a SERM, blocks filovirus entry indirectly by affecting the function of NPC1 (Shoemaker et al., 2013), toremifene is thought to bind the GP molecule directly, to decrease its stability, and thus to prevent the fusion between the viral envelope and endosomal membrane. Interestingly, drugs such as toremifene, bepridil, paroxetine and sertraline seem to interact with V66 in the cavity on the GP surface (Fig. 6) (Ren et al., 2018; Zhao et al., 2016). It is conceivable that the interactions of inhibitors with the GP base involving V66 may affect the structural flexibility or stability of the GP molecule, resulting in reduced membrane fusion activity (Ren et al., 2018; Shaikh et al., 2019). However other possible mechanisms caused by HUP2976 (e.g., cholesterol accumulation in endosomes and inhibitory effects on proteolytic cleavage of GP) are not ruled out.

Although direct evidence needs to be provided, escape mutations of amino acids D47 and V66 suggest that HUP2976 may interact with this cavity like other previously found fusion inhibitors such as toremifene, bepridil, paroxetine and sertraline. However, the amino acid comparison among filovirus GPs (Fig. 5D) suggests that D47 and V66 are not the only amino acids that are involved in the interaction between HUP2976 and GP. EBOV, BDBV, and TAFV GPs are identical at these positions but EBOV and BDBV GPs are more sensitive to HUP2976 than TAFV GP, and RESTV and SUDV GPs having E47 
and V66 displayed differential sensitivities to HUP2976. Detailed molecular mechanisms of HUP2976-mediated fusion inhibition, including identification of the amino acids responsible for the HUP2976-GP interaction, need to be clarified in future studies.

Although many entry inhibitors against EBOV such as ion channel blockers (e.g., amiodarone and bepridil), antimicrobials (e.g., amodiaquine and teicoplanin), psychoactive drugs (e.g., benztropine and imipramine), and protein kinase inhibitors (e.g., erlotinib and sunitinib) have been reported, none of them have been approved by the the United States Food and Drug Administration for the treatment of EVD (Salata et al., 2019). It has been reported that most of these drug candidates inhibit ebolavirus infection by affecting host intracellular factors such as NPC1, host protease cathepsin, calcium signaling required for endosomal fusion, and so on. It should be considered that such compounds that affect cellular functions may have the potential to cause detrimental effects in clinical use. Although further studies are required, candidate compounds that interfere with the GP function by direct interactions with the GP molecule may be promising candidates for the development of EVD drugs in the future.

Other viral proteins are also useful targets to develop EVD therapeutics. For example, NP, VP35, and VP24 play key roles in the life cycle of ebolaviruses by mediating nucleocapsid transport (Takamatsu et al., 2018). Inhibition of the functions of these proteins may reduce the replication efficiency of filoviruses. Indeed, it was reported that siRNA therapeutics targeting VP24 and VP35 might be one of the options as indicated by their efficacy in nonhuman primate models (Geisbert et al., 2010; Warren et al., 2010). Interactions between VP40 and other host proteins may also be an interesting target. Further studies on drug design focusing on therapeutic agents that directly inhibit viral protein functions and/or interfere with viral-host protein interaction are needed. 


\section{Acknowledgements}

We thank Dr. K. Maenaka and Ms. S. Otsuguro (Center for Research and Education on Drug Discovery, Hokkaido University) for supporting the project and Mr. K. Barrymore for editing the manuscript.

\section{Funding}

This work was supported by KAKENHI (16H02627), a Grant-in-Aid for Scientific Research from the Ministry of Education, Culture, Sports, Science and Technology (MEXT), Platform Project for Supporting Drug Discovery and Life Science Research (Basis for Supporting Innovative Drug Discovery and Life Science Research [BINDS] and Platform for Drug Discovery, Informatics, and Structural Life Science [PDIS])(JP19am0101001), the Japanese Initiative for Progress of Research on Infectious Disease for Global Epidemics (J-PRIDE)(JP17fm0208101 and JP18fm0208101), and Translational Research Network Program (JP15lm0103004) from the Japan Agency for Medical Research and Development (AMED), and a grant-in-aid from the Northern Advancement Centre for Science and Technology (NOASTEC) Foundation (H28S-2-12). The work was also funded in part by the Intramural Research Program, NIAID, NIH.

\section{References}

Alvarez, C.P., Lasala, F., Carrillo, J., Muñiz, O., Corbí, A.L., Delgado, R., 2002. CType Lectins DC-SIGN and L-SIGN Mediate Cellular Entry by Ebola Virus in cis and in trans . J. Virol. 76, 6841-6844. https://doi.org/10.1128/jvi.76.13.68416844.2002

Bai, C.Q., Mu, J.S., Kargbo, D., Song, Y. Bin, Niu, W.K., Nie, W.M., Kanu, A., Liu, 
W.W., Wang, Y.P., Dafae, F., Yan, T., Hu, Y., Deng, Y.Q., Lu, H.J., Yang, F., Zhang, X.G., Sun, Yang, Cao, Y.X., Su, H.X., Sun, Yu, Liu, W. Sen, Wang, C.Y., Qian, J., Liu, L., Wang, H., Tong, Y.G., Liu, Z.Y., Chen, Y.S., Wang, H.Q., Kargbo, B., Gao, G.F., Jiang, J.F., 2016. Clinical and Virological Characteristics of Ebola Virus Disease Patients Treated with Favipiravir (T-705) - Sierra Leone, 2014. Clin. Infect. Dis. 63, 1288-1294. https://doi.org/10.1093/cid/ciw571

Baseler, L., Chertow, D.S., Johnson, K.M., Feldmann, H., Morens, D.M., 2017. The Pathogenesis of Ebola Virus Disease. Annu. Rev. Pathol. Mech. Dis. 12, 387-418. https://doi.org/10.1146/annurev-pathol-052016-100506

Basler, C.F., Wang, X., Muhlberger, E., Volchkov, V., Paragas, J., Klenk, H.-D., Garcia-Sastre, A., Palese, P., 2000. The Ebola virus VP35 protein functions as a type I IFN antagonist. Proc. Natl. Acad. Sci. 97, 12289-12294. https://doi.org/10.1073/pnas.220398297

Cagigi, A., Misasi, J., Ploquin, A., Stanley, D.A., Ambrozak, D., Tsybovsky, Y., Mason, R.D., Roederer, M., Sullivan, N.J., 2018. Vaccine Generation of Protective Ebola Antibodies and Identification of Conserved B-Cell Signatures. J. Infect. Dis. 218, S528-S536. https://doi.org/10.1093/infdis/jiy333

Cardile, A.P., Downey, L.G., Wiseman, P.D., Warren, T.K., Bavari, S., 2016. Antiviral therapeutics for the treatment of Ebola virus infection. Curr. Opin. Pharmacol. 30, 138-143. https://doi.org/10.1016/j.coph.2016.08.016

Carette, J.E., Raaben, M., Wong, A.C., Herbert, A.S., Obernosterer, G., Mulherkar, N., Kuehne, A.I., Kranzusch, P.J., Griffin, A.M., Ruthel, G., Cin, P.D., Dye, J.M., Whelan, S.P., Chandran, K., Brummelkamp, T.R., 2011. Ebola virus entry requires the cholesterol transporter Niemann-Pick C1. Nature 477, 340-343. https://doi.org/10.1038/nature10348

Côté, M., Misasi, J., Ren, T., Bruchez, A., Lee, K., Filone, C.M., Hensley, L., Li, Q., Ory, D., Chandran, K., Cunningham, J., 2011. Small molecule inhibitors reveal Niemann-Pick C1 is essential for Ebola virus infection. Nature 477, 344-348. https://doi.org/10.1038/nature10380

Ebihara, H., Theriault, S., Neumann, G., Alimonti, J.B., Geisbert, J.B., Hensley, L.E., Groseth, A., Jones, S.M., Geisbert, T.W., Kawaoka, Y., Feldmann, H., 2007. In Vitro and In Vivo Characterization of Recombinant Ebola Viruses Expressing Enhanced Green Fluorescent Protein. J. Infect. Dis. 196, S313-S322. https://doi.org/10.1086/520590

Emanuel, J., Marzi, A., Feldmann, H., 2018. Filoviruses: Ecology, Molecular Biology, and Evolution. Adv. Virus Res. 100, 189-221. 
https://doi.org/10.1016/bs.aivir.2017.12.002

Furuyama, W., Marzi, A., Nanbo, A., Haddock, E., Maruyama, J., Miyamoto, H.,

Igarashi, M., Yoshida, R., Noyori, O., Feldmann, H., Takada, A., 2016. Discovery of an antibody for pan-ebolavirus therapy. Sci. Rep. 6, 20514.

https://doi.org/10.1038/srep20514

Furuyama, W., Miyamoto, H., Yoshida, R., Takada, A., 2017. Quantification of

Filovirus Glycoprotein-Specific Antibodies. Humana Press, New York, NY, pp.

309-320. https://doi.org/10.1007/978-1-4939-7116-9_25

Geisbert, T.W., Lee, A.C., Robbins, M., Geisbert, J.B., Honko, A.N., Sood, V.,

Johnson, J.C., de Jong, S., Tavakoli, I., Judge, A., Hensley, L.E., MacLachlan, I.,

2010. Postexposure protection of non-human primates against a lethal Ebola virus challenge with RNA interference: a proof-of-concept study. Lancet 375, 1896-

1905. https://doi.org/10.1016/S0140-6736(10)60357-1

Goldstein, T., Anthony, S.J., Gbakima, A., Bird, B.H., Bangura, J., Tremeau-Bravard,

A., Belaganahalli, M.N., Wells, H.L., Dhanota, J.K., Liang, E., Grodus, M., Jangra,

R.K., DeJesus, V.A., Lasso, G., Smith, B.R., Jambai, A., Kamara, B.O., Kamara,

S., Bangura, W., Monagin, C., Shapira, S., Johnson, C.K., Saylors, K., Rubin,

E.M., Chandran, K., Lipkin, W.I., Mazet, J.A.K., 2018. The discovery of Bombali virus adds further support for bats as hosts of ebolaviruses. Nat. Microbiol. 3,

1084-1089. https://doi.org/10.1038/s41564-018-0227-2

Hunt, C.L., Lennemann, N.J., Maury, W., 2012. Filovirus entry: A novelty in the viral fusion world. Viruses 4, 258-275. https://doi.org/10.3390/v4020258

Jasenosky, L.D., Kawaoka, Y., 2004. Filovirus budding. Virus Res. 106, 181-188.

https://doi.org/10.1016/j.virusres.2004.08.014

Johansen, L.M., DeWald, L.E., Shoemaker, C.J., Hoffstrom, B.G., Lear-Rooney, C.M.,

Stossel, A., Nelson, E., Delos, S.E., Simmons, J.A., Grenier, J.M., Pierce, L.T., Pajouhesh, H., Lehár, J., Hensley, L.E., Glass, P.J., White, J.M., Olinger, G.G., 2015. A screen of approved drugs and molecular probes identifies therapeutics with anti-Ebola virus activity. Sci. Transl. Med. 7.

https://doi.org/10.1126/scitranslmed.aaa5597

King, L.B., West, B.R., Schendel, S.L., Saphire, E.O., 2018. The structural basis for filovirus neutralization by monoclonal antibodies. Curr. Opin. Immunol. 53, 196202. https://doi.org/10.1016/j.coi.2018.05.001

Kondoh, T., Letko, M., Munster, V.J., Manzoor, R., Maruyama, J., Furuyama, W., Miyamoto, H., Shigeno, A., Fujikura, D., Takadate, Y., Yoshida, R., Igarashi, M., Feldmann, H., Marzi, A., Takada, A., 2018. Single-Nucleotide Polymorphisms in 
Human NPC1 Influence Filovirus Entry Into Cells. J. Infect. Dis. 218, S397-S402. https://doi.org/10.1093/infdis/jiy248

Kondratowicz, A.S., Lennemann, N.J., Sinn, P.L., Davey, R.A., Hunt, C.L., MollerTank, S., Meyerholz, D.K., Rennert, P., Mullins, R.F., Brindley, M., Sandersfeld, L.M., Quinn, K., Weller, M., McCray, P.B., Chiorini, J., Maury, W., 2011. T-cell immunoglobulin and mucin domain 1 (TIM-1) is a receptor for Zaire Ebolavirus and Lake Victoria Marburgvirus. Proc. Natl. Acad. Sci. 108, 8426-8431.

https://doi.org/10.1073/pnas.1019030108

Kuroda, M., Fujikura, D., Nanbo, A., Marzi, A., Noyori, O., Kajihara, M., Maruyama, J., Matsuno, K., Miyamoto, H., Yoshida, R., Feldmann, H., Takada, A., 2015. Interaction between TIM-1 and NPC1 Is Important for Cellular Entry of Ebola Virus. J. Virol. 89, 6481-6493. https://doi.org/10.1128/JVI.03156-14

Mbala-Kingebeni, P., Aziza, A., Di Paola, N., Wiley, M.R., Makiala-Mandanda, S., Caviness, K., Pratt, C.B., Ladner, J.T., Kugelman, J.R., Prieto, K., Chitty, J.A., Larson, P.A., Beitzel, B., Ayouba, A., Vidal, N., Karhemere, S., Diop, M., Diagne, M.M., Faye, M., Faye, O., Aruna, A., Nsio, J., Mulangu, F., Mukadi, D., Mukadi, P., Kombe, J., Mulumba, A., Villabona-Arenas, C.-J., Pukuta, E., Gonzalez, J., Bartlett, M.L., Sozhamannan, S., Gross, S.M., Schroth, G.P., Tim, R., Zhao, J.J., Kuhn, J.H., Diallo, B., Yao, M., Fall, I.S., Ndjoloko, B., Mossoko, M., Lacroix, A., Delaporte, E., Sanchez-Lockhart, M., Sall, A.A., Muyembe-Tamfum, J.-J., Peeters, M., Palacios, G., Ahuka-Mundeke, S., 2019. Medical countermeasures during the 2018 Ebola virus disease outbreak in the North Kivu and Ituri Provinces of the Democratic Republic of the Congo: a rapid genomic assessment. Lancet Infect. Dis. 3099, 1-10. https://doi.org/10.1016/S1473-3099(19)30118-5

Miller, E.H., Obernosterer, G., Raaben, M., Herbert, A.S., Deffieu, M.S., Krishnan, A., Ndungo, E., Sandesara, R.G., Carette, J.E., Kuehne, A.I., Ruthel, G., Pfeffer, S.R., Dye, J.M., Whelan, S.P., Brummelkamp, T.R., Chandran, K., 2012. Ebola virus entry requires the host-programmed recognition of an intracellular receptor. EMBO J. 31, 1947-1960. https://doi.org/10.1038/emboj.2012.53

Misasi, J., Gilman, M.S.A., Kanekiyo, M., Gui, M., Cagigi, A., Mulangu, S., Corti, D., Ledgerwood, J.E., Lanzavecchia, A., Cunningham, J., Muyembe-Tamfun, J.J., Baxa, U., Graham, B.S., Xiang, Y., Sullivan, N.J., McLellan, J.S., 2016. Structural and molecular basis for Ebola virus neutralization by protective human antibodies. Science (80-. ). 351, 1343-1346. https://doi.org/10.1126/science.aad6117 Nakayama, E., Tomabechi, D., Matsuno, K., Kishida, N., Yoshida, R., Feldmann, H., Takada, A., 2011. Antibody-dependent enhancement of marburg virus infection. J. 
Infect. Dis. 204. https://doi.org/10.1093/infdis/jir334

Nakkazi, E., 2018. Randomised controlled trial begins for Ebola therapeutics. Lancet (London, England) 392, 2338. https://doi.org/10.1016/S0140-6736(18)33011-3

Nanbo, A., Kawaoka, Y., Imai, M., Takahashi, K., Watanabe, S., Noda, T., Neumann, G., Halfmann, P., 2010. Ebolavirus Is Internalized into Host Cells via Macropinocytosis in a Viral Glycoprotein-Dependent Manner. PLoS Pathog. 6, e1001121. https://doi.org/10.1371/journal.ppat.1001121

NIH, 2019. Clinical Trial of Investigational Ebola Treatments Begins in the Democratic Republic of the Congo | NIH: National Institute of Allergy and Infectious Diseases [WWW Document]. https://doi.org/https://www.niaid.nih.gov/newsevents/clinical-trial-investigational-ebola-treatments-begins-democratic-republiccongo

Noda, T., Sagara, H., Suzuki, E., Takada, A., Kida, H., Kawaoka, Y., 2002. Ebola Virus VP40 Drives the Formation of Virus-Like Filamentous Particles Along with GP. J. Virol. 76, 4855-4865. https://doi.org/10.1128/jvi.76.10.4855-4865.2002

Ren, J., Zhao, Y., Fry, E.E., Stuart, D.I., 2018. Target Identification and Mode of Action of Four Chemically Divergent Drugs against Ebolavirus Infection. J. Med. Chem. 61, 724-733. https://doi.org/10.1021/acs.jmedchem.7b01249

Rollin, P.E., Williams, R.J., Bressler, D.S., Pearson, S., Cottingham, M., Pucak, G., Sanchez, A., Trappier, S.G., Peters, R.L., Greer, P.W., Zaki, S., Demarcus, T., Hendricks, K., Kelley, M., Simpson, D., Geisbert, T.W., Jahrling, P.B., Peters, C.J., Ksiazek, T.G., 1999. Ebola (Subtype Reston) Virus among Quarantined Nonhuman Primates Recently Imported from the Philippines to the United States. J. Infect. Dis. 179, S108-S114. https://doi.org/10.1086/514303

Saeed, M.F., Kolokoltsov, A.A., Albrecht, T., Davey, R.A., 2010. Cellular entry of ebola virus involves uptake by a macropinocytosis-like mechanism and subsequent trafficking through early and late endosomes. PLoS Pathog. 6. https://doi.org/10.1371/journal.ppat.1001110

Sahul Hameed, A.S., Ninawe, A.S., Nakai, T., Chi, S.C., Johnson, K.L., 2019. ICTV virus taxonomy profile: Nodaviridae. J. Gen. Virol. 100, 3-4. https://doi.org/10.1099/jgv.0.001170

Saito, S., Sano, K., Suzuki, T., Ainai, A., Taga, Y., Ueno, T., Tabata, K., Saito, K., Wada, Y., Ohara, Y., Takeyama, H., Odagiri, T., Kageyama, T., Ogawa-Goto, K., Multihartina, P., Setiawaty, V., Pangesti, K.N.A., Hasegawa, H., 2019. IgA tetramerization improves target breadth but not peak potency of functionality of anti-influenza virus broadly neutralizing antibody. PLoS Pathog. 15, 1-23. 
https://doi.org/10.1371/journal.ppat.1007427

Salata, C., Calistri, A., Alvisi, G., Celestino, M., Parolin, C., Palù, G., Salata, C., Calistri, A., Alvisi, G., Celestino, M., Parolin, C., Palù, G., 2019. Ebola Virus Entry: From Molecular Characterization to Drug Discovery. Viruses 11, 274. https://doi.org/10.3390/v11030274

Schornberg, K., Matsuyama, S., Kabsch, K., Delos, S., Bouton, A., White, J., 2006.

Role of Endosomal Cathepsins in Entry Mediated by the Ebola Virus

Glycoprotein. J. Virol. 80, 4174-4178. https://doi.org/10.1128/JVI.80.8.41744178.2006

Shaikh, F., Zhao, Y., Alvarez, L., Iliopoulou, M., Lohans, C.T., Schofield, C.J., PadillaParra, S., Siu, S.W.I., Fry, E., Ren, J., Stuart, D.I., 2019. Structure-based In Silico Screening Identifies a Potent Ebolavirus Inhibitor from a Traditional Chinese Medicine Library. J. Med. Chem. https://doi.org/10.1021/acs.jmedchem.8b01328 Shoemaker, C.J., Schornberg, K.L., Delos, S.E., Scully, C., Pajouhesh, H., Olinger, G.G., Johansen, L.M., White, J.M., 2013. Multiple Cationic Amphiphiles Induce a Niemann-Pick C Phenotype and Inhibit Ebola Virus Entry and Infection. PLoS One 8. https://doi.org/10.1371/journal.pone.0056265

Sissoko, D., Laouenan, C., Folkesson, E., M’Lebing, A.B., Beavogui, A.H., Baize, S., Camara, A.M., Maes, P., Shepherd, S., Danel, C., Carazo, S., Conde, M.N., Gala, J.L., Colin, G., Savini, H., Bore, J.A., Le Marcis, F., Koundouno, Fara Raymond, Petitjean, F., Lamah, M.C., Diederich, S., Tounkara, A., Poelart, G., Berbain, E., Dindart, J.M., Duraffour, S., Lefevre, A., Leno, T., Peyrouset, O., Irenge, L., Bangoura, N., Palich, R., Hinzmann, J., Kraus, A., Barry, T.S., Berette, S., Bongono, A., Camara, M.S., Chanfreau Munoz, V., Doumbouya, L., Souley Harouna, Kighoma, P.M., Koundouno, Fara Roger, Réné Lolamou, Loua, C.M., Massala, V., Moumouni, K., Provost, C., Samake, N., Sekou, C., Soumah, A., Arnould, I., Komano, M.S., Gustin, L., Berutto, C., Camara, D., Camara, F.S., Colpaert, J., Delamou, L., Jansson, L., Kourouma, E., Loua, M., Malme, K., Manfrin, E., Maomou, A., Milinouno, A., Ombelet, S., Sidiboun, A.Y., Verreckt, I., Yombouno, P., Bocquin, A., Carbonnelle, C., Carmoi, T., Frange, P., Mely, S., Nguyen, V.K., Pannetier, D., Taburet, A.M., Treluyer, J.M., Kolie, J., Moh, R., Gonzalez, M.C., Kuisma, E., Liedigk, B., Ngabo, D., Rudolf, M., Thom, R., Kerber, R., Gabriel, M., Di Caro, A., Wölfel, R., Badir, J., Bentahir, M., Deccache, Y., Dumont, C., Durant, J.F., El Bakkouri, K., Gasasira Uwamahoro, M., Smits, B., Toufik, N., Van Cauwenberghe, S., Ezzedine, K., Dortenzio, E., Pizarro, L., Etienne, A., Guedj, J., Fizet, A., Barte de Sainte Fare, E., Murgue, B., Tran-Minh, 
T., Rapp, C., Piguet, P., Poncin, M., Draguez, B., Allaford Duverger, T., Barbe, S., Baret, G., Defourny, I., Carroll, M., Raoul, H., Augier, A., Eholie, S.P., Yazdanpanah, Y., Levy-Marchal, C., Antierrens, A., Van Herp, M., Günther, S., de Lamballerie, X., Keïta, S., Mentre, F., Anglaret, X., Malvy, D., 2016. Experimental Treatment with Favipiravir for Ebola Virus Disease (the JIKI Trial): A Historically Controlled, Single-Arm Proof-of-Concept Trial in Guinea. PLoS Med. 13, 1-36. https://doi.org/10.1371/journal.pmed.1001967

Takada, A., Feldmann, H., Stroeher, U., Bray, M., Watanabe, S., Ito, H., Mcgregor, M., Kawaoka, Y., 2003. Identification of Protective Epitopes on Ebola Virus Glycoprotein at the Single Amino Acid Level by Using Recombinant Vesicular Stomatitis Viruses. J. Virol. 77, 1069-1074. https://doi.org/10.1128/JVI.77.2.1069 Takada, A., Fujioka, K., Tsuiji, M., Morikawa, A., Higashi, N., Ebihara, H., Kobasa, D., Feldmann, H., Irimura, T., Kawaoka, Y., 2004. Human macrophage C-type lectin specific for galactose and $\mathrm{N}$-acetylgalactosamine promotes filovirus entry. J. Virol. 78, 2943-7. https://doi.org/10.1128/JVI.78.6.2943

Takada, A., Robison, C., Goto, H., Sanchez, A., Murti, K.G., Whitt, M.A., Kawaoka, Y., 1997. A system for functional analysis of Ebola virus glycoprotein. Proc. Natl. Acad. Sci. U. S. A. 94, 14764-9. https://doi.org/https://doi.org/10.1073/pnas.94.26.14764

Takamatsu, Y., Kolesnikova, L., Becker, S., 2018. Ebola virus proteins NP, VP35, and VP24 are essential and sufficient to mediate nucleocapsid transport. Proc. Natl. Acad. Sci. 115, 1075-1080. https://doi.org/10.1073/pnas.1712263115

Tariq, A., Roosa, K., Mizumoto, K., Chowell, G., 2019. Assessing reporting delays and the effective reproduction number: The Ebola epidemic in DRC, May 2018January 2019. Epidemics 26, 128-133. https://doi.org/10.1016/j.epidem.2019.01.003

The PREVAIL II Writing Group, 2016. A Randomized, Controlled Trial of ZMapp for Ebola Virus Infection. N. Engl. J. Med. 375, 1448-1456.

https://doi.org/10.1056/nejmoa1604330

Tiller, T., Meffre, E., Yurasov, S., Tsuiji, M., Nussenzweig, M.C., Wardemann, H., 2008. Efficient generation of monoclonal antibodies from single human B cells by single cell RT-PCR and expression vector cloning. J. Immunol. Methods 329, $112-$ 24. https://doi.org/10.1016/j.jim.2007.09.017

Warren, T.K., Warfield, K.L., Wells, J., Swenson, D.L., Donner, K.S., Van Tongeren, S.A., Garza, N.L., Dong, L., Mourich, D. V., Crumley, S., Nichols, D.K., Iversen, P.L., Bavari, S., 2010. Advanced antisense therapies for postexposure protection 
against lethal filovirus infections. Nat. Med. 16, 991-994.

https://doi.org/10.1038/nm.2202

WHO, 2019. Ebola | Ebola situation reports: Democratic Republic of the Congo. WHO. https://www.who.int/ebola/situation-reports/drc-2018/en/

WHO, 2018. Ebola | Ebola treatments approved for compassionate use in current outbreak. WHO. https://www.who.int/ebola/drc-2018/treatments-approved-forcompassionate-use/en/

Zhang, A.P.P., Abelson, D.M., Bornholdt, Z.A., Liu, T., Woods, V.L., Saphire, E.O., 2012. The ebolavirus VP24 interferon antagonist: Know your enemy. Virulence 3, 440-445. https://doi.org/10.4161/viru.21302

Zhao, Y., Ren, J., Fry, E.E., Xiao, J., Townsend, A.R., Stuart, D.I., 2018. Structures of Ebola Virus Glycoprotein Complexes with Tricyclic Antidepressant and Antipsychotic Drugs. J. Med. Chem. 61, 4938-4945.

https://doi.org/10.1021/acs.jmedchem.8b00350

Zhao, Y., Ren, J., Harlos, K., Jones, D.M., Zeltina, A., Bowden, T.A., Padilla-Parra, S., Fry, E.E., Stuart, D.I., 2016. Toremifene interacts with and destabilizes the Ebola virus glycoprotein. Nature 535, 169-172. https://doi.org/10.1038/nature18615 


\section{Figure legends}

Fig. 1. HUP2976 and its inhibitory activity against VSVs pseudotyped with filovirus GPs. (A) Chemical structure of HUP2976 (MW: 470.6). (B) Pseudotyped VSVs (1,000 IU/ml) were mixed with equal volumes of HUP2976 and inoculated onto Vero E6 and Huh7 cells in 96-well plates. The cells were incubated at $37^{\circ} \mathrm{C}$ for $18 \mathrm{hr}$ and the numbers of GFP-expressing cells were counted using IN Cell Analyzer. One experiment performed in triplicate is shown; averages and standard deviations are presented. (C) Vero E6 and Huh7 cells were incubated with the indicated concentrations of HUP2976 or $0.8 \%$ DMSO. Cell viabilities were measured after 24 hour-incubation.

Fig. 2. Inhibitory activity of HUP2976 against EBOV-GFP. EBOV-GFP was diluted to infect Vero E6 cells at high (0.5-1.0) and low (0.05-0.1) multiplicities of infection. Following infection, the cells were incubated with the indicated concentrations of HUP2976 for 2 days and fluorescent images were captured (A). EBOV-GFP was diluted (200 focus forming units/well) and inoculated to Vero E6 cells on 96-well plates. Then, the cells were incubated as described in Materials and Methods. The numbers of GFPexpressing foci were counted from triplicate wells (low moi samples) and averages and standard deviations are shown (B). Statistical analysis was performed using Student's $t$ test $(* \mathrm{p}<0.05)$

Fig. 3. Membrane fusion inhibition by HUP2976. DiI-labelled VLPs (red) were inoculated into confluent Vero E6 cells expressing eGFP-Rab7 (green) and incubated for 30 min on ice. After adsorption, the cells were incubated for 0 (A,B), 2 (C,D), or $6 \mathrm{hrs}$ 
(E,F) at $37^{\circ} \mathrm{C}$ in the presence of HUP2976 $(25 \mu \mathrm{M})$ or $0.25 \%$ DMSO. The cells were fixed with $4 \%$ paraformaldehyde and nuclei were stained with DAPI (blue). DiI signals on the cell surface and in the cytoplasm were monitored by confocal laser scanning microscopy (A,C,E). Scale bars represent $10 \mu \mathrm{m}$. (B,D,F) Three microscopic fields were acquired randomly, and the number of DiI-labeled virions was measured in approximately 50 individual cells $(B, D)$. Percentage of colocalization (D) and size $(B, F)$ and fluorescence intensity (F) of DiI dots were measured in approximately 50 individual cells and quantified using Image $\mathbf{J}$ software. Averages and standard deviations of three independent experiments are shown (B,D,F). Statistical analysis was performed using Student's $t$-test $\left({ }^{*} \mathrm{p}<0.05\right)$. (G) Vero E6/eGFP-Rab7 cells were incubated with HUP2976 (25 $\left.\mu \mathrm{M}\right)$, $\mathrm{NH}_{4} \mathrm{Cl}(25 \mathrm{mM})$, or DMSO (0.25\%) and stained with LysoTracker Red DND-99. Acidic endosomes are viualized in red.

Fig. 4. Effect of HUP2976 on the GP-NPC1 interaction. ELISA plates were coated with thermolysin-treated VLPs, followed by incubation with HUP2976 or mAb114, HAtagged NPC1 or mock cell lysates, a rat anti-HA antibody, and HRP-conjugated anti-rat $\operatorname{IgG}(\mathrm{H}+\mathrm{L})$. The reaction was visualized with the TMB substrate. The OD values of mock cell lysates were subtracted from those of HUP2976- or mAb114-treated lysates at each concentration. The experiment was performed in triplicate and averages and standard deviations are shown .

Fig. 5. Identification of amino acid substitutions allowing escape in EBOV GP. (A) The primary structure of GP and amino acid sequences at positions 45-70 are shown. The primary GP structure contains the base, glycan cap, mucin-like domain (MLD), internal 
fusion loop (IFL), and transmembrane region (TM) and cytoplasmic tail (CT). Amino acid substitutions found in the EBOV GP escape mutants selected under HUP2976 pressure are shown in red. (B) The trimeric structure of EBOV GP (PDB code: 6G95) was constructed using PyMOL 1.2r3pre (Schrödinger) and the colored corresponding sequence map above. (C) VSVs pseudotyped with wildtype and mutant EBOV GPs were diluted to 1,000 IU/ml, mixed with equal volumes of HUP2976, and inoculated onto Vero E6 cells. The cells were incubated at $37^{\circ} \mathrm{C}$ for $18 \mathrm{hr}$, and GFP-expressing cells were counted with IN Cell Analyzer. Averages and standard deviations from 3 independent experiments are shown. (D) Amino acid sequences at positions 45-70 (EBOV numbering) of ebolavirus and marburgvirus GPs. Amino acid residues conserved among all of the filoviruses and those conserved among all of the ebolaviruses but not marburgvirus are highlighted in light blue and pink, respectively.

Fig. 6. Substituted amino acid residues mapped on the GP trimeric structure. The amino acid residues at positions 47 ad 66 are mapped on a ribbon model (A) and surface model (B) of the EBOV GP trimeric structure constructed using PyMOL 1.2r3pre (Schrödinger) based on the crystal structure (PDB code: 6G95). A close-up of the EBOV GP inhibitor-binding pocket in a surface representation in the solid black square. GP1 and GP2 are shown in black and orange in a GP monomer and in gray and yellow in another monomer, respectively. Green and red spheres represent D47 and V66 residues, respectively. 